\title{
Narratives of mothers of children with autism spectrum disorders: focus on eating behavior
}

\author{
Narrativa de mães de crianças com transtorno do espectro do autismo: foco no \\ comportamento alimentar
}

Cristiane P. Lázaro, Milena P. Pondé*

\begin{abstract}
Objective: To investigate the eating behavior of individuals with autism through their mothers' narratives.

Methods: The study of narratives was used to report on the narrators' experiences. Data on the eating habits of individuals with autism were collected using semi-structured interviews held individually with the mothers. The interviews were recorded, transcribed and codified using the NVivo software program.

Results: Eighteen mothers of boys/young men with autism participated in the study. Analysis yielded three major categories: eating patterns, the family's attitudes to the child's eating habits, and food-related behavior.

Conclusion: Results show that autism-related factors may affect the child's food choices. Environmental factors, particularly the parents' behavior, may also play a decisive role, both in reinforcing the child's food choices and in encouraging a healthier and more diversified diet. Professionals should instruct parents regarding their decisive role in reinforcing or discouraging inappropriate mealtime behavior in children with autism.

Keywords: Autism spectrum, behavior problems, parents' style, qualitative methods, eating and feeding disorders.
\end{abstract}

\section{Resumo}

Objetivo: Investigar o comportamento alimentar de indivíduos com transtorno do espectro do autismo (TEA) através das narrativas de suas mães.

Métodos: Os dados sobre os hábitos alimentares dos indivíduos com TEA foram coletados utilizando entrevistas semiestruturadas realizadas individualmente com as mães. As entrevistas foram gravadas, transcritas e codificadas usando o programa NVivo.

Resultados: Dezoito mães de meninos/jovens homens com autismo participaram do estudo. A análise produziu três categorias principais: padrões alimentares, a atitude da família em relação aos hábitos alimentares da criança e comportamentos relacionados à alimentação.

Conclusão: Os resultados mostram que os fatores relacionados ao autismo podem afetar as escolhas alimentares da criança. Os fatores ambientais, particularmente o comportamento dos pais, também podem desempenhar um papel decisivo, tanto no reforço das escolhas alimentares da criança quanto no incentivo a uma dieta mais saudável e diversificada. Os profissionais devem instruir os pais sobre o seu papel decisivo no reforço ou desencorajamento do comportamento inapropriado nas refeições em crianças com TEA.

Descritores: Transtorno do espectro do autismo, problemas de comportamento, estilo dos pais, métodos qualitativos, transtornos alimentares.

\footnotetext{
* Laboratório Interdisciplinar de Pesquisa em Autismo (LABIRINTO), Escola Bahiana de Medicina e Saúde Pública (BAHIANA), Salvador, BA, Brazil. Submitted Jan 11 2017, accepted for publication Apr 162017.

Suggested citation: Lázaro CP, Pondé MP. Narratives of mothers of children with autism spectrum disorders: focus on eating behavior. Trends Psychiatry Psychother. 2017;39(3):180-187. http://dx.doi.org/10.1590/2237-6089-2017-0004
} 


\section{Introduction}

Autism spectrum disorders (ASD) are characterized by deficits in social communication and interaction, as well as stereotyped behavior. ${ }^{1}$ The disorder has a heterogenous phenotype, in relation to both symptoms and severity. ${ }^{2}$ Several studies conducted from the point of view of the healthcare professional/physician indicated that individuals with ASD are resistant to change and have a narrow range of interests that may affect even the food they eat. Some authors have suggested that children with autism tend to restrict their diet to an extremely narrow range of foods, with associated food neophobia and sensory problems. ${ }^{3}$ Furthermore, sensory factors such as smell, texture, color and temperature may contribute to this behavior. ${ }^{4-6} \mathrm{~A}$ literature review of seven descriptive studies found the prevalence of eating problems in children with ASD to range between 46 and $89 \%$ in the patients evaluated. ${ }^{7}$ The most common problems found in those studies were: limited food intake; refusal to eat certain foods or selectivity related to the texture, smell and taste of food; inflexibility regarding the use of utensils, brands and packaging; and behavioral and nutritional problems. ${ }^{7} \mathrm{~A}$ later review covering the preceding 25 years and including 12 intervention studies with designs and methods based on food records, questionnaires, or interviews involving parent reports confirmed selectivity as a significant issue in ASD, emphasizing its association with sensory dysfunctions. ${ }^{4}$ A recent meta-analysis indicated that children with ASD are four times more likely to have eating problems compared to their peers with typical development (odds ratio $[\mathrm{OR}]=5.11 ; 95 \%$ confidence interval $[95 \% \mathrm{CI}] 3.74-6.97) .{ }^{8}$ All the above-mentioned studies dealt with eating problems in patients with ASD from the perspective of the healthcare professional/ physician, with no information on the perceptions and concerns of parents in relation to the eating habits of individuals with ASD.

A study suggested that the parents' perception of their autistic children differs in various aspects from the perception of the professionals who provide care and/or evaluate those children. ${ }^{9}$ In a qualitative study conducted according to the established theory, Rogers et al. ${ }^{10}$ asked mothers to describe the eating-related challenges that they had had to deal with over time and the strategies developed to solve them. Three patterns of restriction were observed: 1) difficulty in feeding the child right from his/her first moments of life, i.e., with the initiation of breastfeeding or the introduction of artificial baby formulae; 2) difficulty arising around the 12 th to the 24th months of life, when the first signs of the disorder began to appear; and 3 ) eating problems at birth that were resolved, but then, at around the 12th to the 24th month, the child developed food-related restrictions. Another problem the mothers noticed was the child's behavioral reaction, often unusual and severe, with respect to his/her aversion to certain foods, making it difficult to guarantee diet adequacy in view of the numerous restrictions imposed by the child. ${ }^{10}$ The mothers also mentioned the difficulty in finding specialist professionals to help them with these problems. Suarez et al. ${ }^{11}$ evaluated family expectations and experiences at mealtimes based on interviews with the parents of autistic children with severe food selectivity. The parents reported that they considered mealtimes chaotic and stressful. The main frustrations reported were: the child's inability to remain seated at the table, the impossibility of eating as a family, and the difficulties involved in diversifying the types of food eaten by the child. These qualitative studies provided important data on eating-related difficulties over a lifetime as well as data on the aspects of the child's eating behavior that the parents considered challenging.

In addition to the specificities of ASD that may contribute to restrictive eating behavior, Curtin et al. ${ }^{12}$ suggested that children with ASD who tend to be highly selective in terms of what they will or will not eat present more behavioral problems at mealtimes, consequently generating greater conjugal stress for their parents. The presence of severe behavioral symptoms in children with ASD was shown to increase the likelihood of the parents suffering from anxiety/depression symptoms by a factor of $35 .{ }^{13}$ Conversely, evidence suggests that parental behavior may affect the prognosis of autism from the child's early years until adulthood. ${ }^{14-16}$ Within this perspective, in order to improve understanding of the eating behavior of the child with ASD, not only the specificities of ASD must be taken into consideration, but also the parents' behavior in relation to the child's dietary restrictions. The present qualitative study investigated the eating behavior of autistic individuals through their mothers' narratives, and also collected information on the family's eating behavior and how the family deals with the child's eating restrictions.

\section{Methods}

\section{Recruitment}

This study was conducted in March and April 2014 at a teaching institute specialized in individuals with ASD. At that school, each child receives individual care from a teacher who is responsible for that child's educational program over a one-year period. While the children 
receive individualized care, the mothers wait on the verandah, singly or in small groups. In this setting, mothers were invited to participate in the present study, were provided with information on the study objectives and were later interviewed individually for approximately 90 minutes.

\section{Participants}

A total of 18 mothers were included. The chosen methodological approach was the study of narratives. Interviews were conducted with the mothers, and the experiences reported by these narrators were analyzed.

\section{Ethics}

The study was approved by the institution's internal review board on March 12, 2014 (reference no. 5551.381). All the participants signed an informed consent form and the survey was conducted in accordance with the Helsinki Declaration.

\section{Data collection and analysis}

In the narrative approach, meaning is sought in past experiences, as well as in the articulation of these experiences with others, revealing the narrators' important life events and experiences. ${ }^{17}$ The number of interviews was considered sufficient and the sample size was considered satisfactory when data saturation occurred. ${ }^{17}$ The semi-structured interviews consisted of questions on the eating and behavioral habits of the individuals with ASD right from the start of breastfeeding until the present day, as well as questions on the family's eating habits. The mothers were also encouraged to talk about any aspects that they considered relevant in relation to their children's diet, thus allowing different topics to be brought up in addition to those raised by the investigator. The interviews were transcribed and entered into the NVivo software program, version 10 . Each interview was carefully read and the parts of the narratives related to eating/nutrition were identified and coded. ${ }^{18}$ These segments were linked to ideas, which were denominated "categories." For each new idea identified, a new category was created on NVivo. As the interviews were read, each segment related to a given category was marked and sent to the corresponding category created in the NVivo program.

\section{Results}

Eighteen mothers of boys and young men with ASD aged 5 to 28 years participated in the study. The mean age of the mothers was 42.2 years. Most were married, with only two being single. Their socioeconomic conditions varied, with incomes that ranged from 525 to 3,700 dollars/month (2-14 minimum salaries/ month). Analysis of the interviews led to the creation of three major categories associated with the mothers' descriptions of the mealtime behavior of their children with ASD: child's eating patterns; family's attitudes in relation to child's eating habits; and food-related behavior (Figure 1).

\section{Child's eating patterns}

This first category reflects the mothers' descriptions with regard to their child's eating habits and refers to the specificities of the child's eating behavior. The following subcategories were found: 1) breastfeeding; 2) chewing; 3) changes in eating behavior; 4) food preferences; and 5) food restrictions.

Feeding in autism spectrum disorder

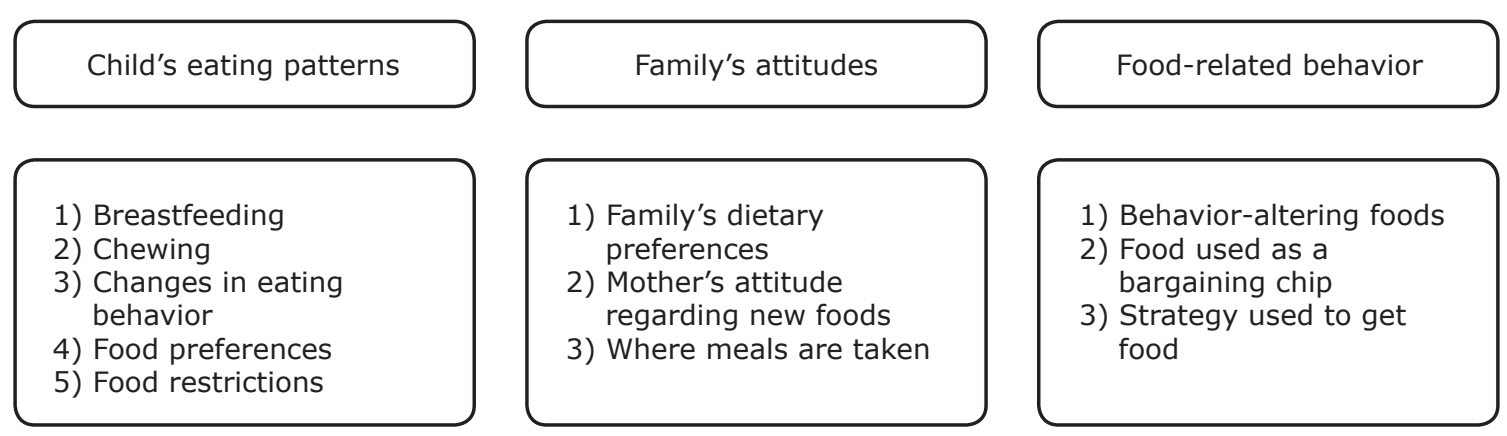

Figure 1 - Food-related aspects in autism spectrum disorders. 
1) Breastfeeding describes how the mother managed this task. Three patterns of breastfeeding were identified:

a) Breastfeeding was interrupted early, generally because the infant refused to breastfeed.

Right from the start, he rejected the breast and only breastfed in the first week. Then I would put him to my breast and he wouldn't want it anymore and would cry and scream with hunger... he tried to suck. It was as if he didn't like it... he would try, then would let it go and start to cry. (Mother of an 8-year-old boy)

b) Other mothers breastfed for periods ranging from six months to two years, supplementing breast milk with formula. The following reasons were given for complementing breast milk with formula: the amount of breast milk was insufficient; the doctor recommended it because the baby cried a lot; by four months the baby began to spit out the breast milk and refused to take it.

c) There were also mothers who continued to breastfeed until the child was 3-5 years of age, even when the child was already consuming a variety of other food items. These mothers did not give any reasons for breastfeeding longer than recommended.

2) Chewing refers to the child's behavior in relation to the introduction of semisolid and solid foods into his diet from the start of weaning up to the present day. Some children swallowed the food without chewing or after chewing only perfunctorily.

I put two plates on the table. One is the plate that he holds, with the fork in his hand, and the other is his plate of food, and I put the food on his plate forkful by forkful and he takes it forkful by forkful. It's the only way I have found to control his eating! (Mother of a 9-year-old boy)

3) Changes in eating behavior with no triggering factor. Subtly, the child would begin refusing food that he had previously eaten.

Before that he loved watermelon, but now he won't eat it unless I make juice from it. (...) He'll take any fruit if it is in the form of juice or a smoothie but he won't eat them. (Mother of a 7-year-old boy)

4) Food preferences. The most commonly consumed foods were rice, beans, potatoes, and blended soup or soup containing instant pasta. Mothers also mentioned a high consumption of various types of cookies, soft cheese-filled buns, processed meats or hamburger, butter, soft drinks, pizza, popcorn, French fries, icecream, chocolate, creamy yoghurt, sausages and bacon. Some of the mothers mentioned that these preferences had been established through siblings or cousins who would consume these food items and offer them to the child, or otherwise, through children at school. Other mothers offered their children these foods as a way of making the child happy.

5) Food restrictions refers to the food items that were rejected by the child.

a) Some types of food were rejected by the children. Many children refused seasoning such as chives, parsley, tomatoes, peppers and coriander to be added to food. Vegetables and legumes were generally rejected. The majority of the children rejected fish. In addition, the majority refused to eat any kind of fruit or only specific kinds of fruit. Other children refused food without any juice or sauce such as barbecued meat.

b) Restrictions were found with respect to the texture of the food. No pattern was found: some children accepted food that was crunchy, dry, wet, raw, cooked, hard, mashed, semi-solid or soft, while others refused it.

c) Some children complained about how the food smells; these children were also found to be intolerant to other aromas.

\section{Family's attitudes in relation to child's eating habits}

This second category reflects the family's attitudes in relation to the child's eating habits, with the following subcategories: 1) family's dietary preferences; 2) mother's attitude regarding new foods; and 3) where meals are eaten.

1) In all interviews, it was mentioned that the family's dietary preferences and habits closely resembled those of the individuals with ASD. Some of the mothers expressed an interest in healthy eating habits, not only for the individual with ASD but also for the whole family. These mothers did not report any significant restrictions in their children's dietary habits at any time in their lives.

2) The mother's attitude regarding new foods also appears to influence the child's eating habits. Some mothers tended to accept the children's refusal to eat even before they tried the food. Other mothers tended not to accept the children's initial refusal to eat the food and invented games to whet their curiosity about it. 
3) Another aspect that was emphasized in this category was the importance given by the family to where meals were eaten. Some families would put the child outdoors at mealtimes or feed the child separately from the other members of the family.

\section{Food-related behavior}

In relation to this third category, the mothers spoke of attitudes and reactions associated with eating that could affect the children's specific eating pattern. The following subcategories emerged: 1 ) behavior-altering foods; 2) food used as a bargaining chip; 3) strategies used to get food; 4) reaction to the foods that are rejected; and 5) reaction to new kinds of foods.

1) Behavior-altering foods. Some kinds of food were seen as behavior-altering. The reactions triggered by eating certain food items were described, ranging from behavior modifications to functional alterations in the organism.

a) Behavioral alterations ranged from reactions such as irritation, euphoria, agitation, aggravation of stereotypes, difficulties sleeping and more frequent crying episodes to more distant and evasive behavior, emphasizing the child's difficulty in interacting socially. These reactions were perceived to be associated with drinking coffee, eating peanuts, chocolate and chocolate-based foods, foods containing gluten, carbonated soft drinks, processed snacks and waffles containing food dyes. The majority of the children suffered some form of modification when they consumed at least two of the above-mentioned foods.

b) With respect to functional alterations in the organism, bowel regularity was found to be affected by gluten intake, triggering constipation, abdominal swelling due to the intense production of gases, absence of stool formation and the presence of viscous feces. Many of the mothers reported that they had consulted professionals regarding the efficacy of a gluten- and lactosefree diet for autistic children; however, they justified not having complied with the diet for financial reasons despite having been curious to see whether it would result in any change in their children's behavior. Only one mother stated that she had excluded gluten and lactose routinely from her son's diet and added that she had started him on this diet prior to receiving confirmation of his diagnosis of ASD, because of her son's gastrointestinal symptoms and behavior. After having his bottle of porridge, the child would stay awake and agitated, and this behavior was particularly evident at night because of his inability to sleep.

2) Food used as a bargaining chip. Since feeding was one of the major concerns reported by the mothers, the use of food as a bargaining chip in the relationship with the children was easily noted. Some of the mothers used this control mechanism with success, since the children ate correctly. In these cases, an incentive was given for the child to finish the meal, e.g., the promise of enjoyable activities or being given a favorite food as a snack. Nevertheless, in the majority of cases, this bargaining resulted in replacing lunch or dinner with a high-calorie dessert or snack. In other words, to get the child to eat something, the solution was to let him eat what he wanted such as a sandwich, cookie, creamy chocolate yoghurt, or a soft drink.

3) Strategies used to get food. The children also developed strategies to get their preferred food. Some of the mothers described the children's regressive, affectionate and/or insistent attitudes to get the food they wanted. It was common for the family member to give the child the food he/she wanted when he/she cried insistently or screamed. In some cases, behaviors became more disruptive, including aggressive attitudes with crying fits and temper tantrums, aggression and self-mutilation.

4) Reaction to the foods that are rejected. The children's reactions to the foods they reject may influence the family's attitudes. Reactions such as nausea and vomiting were defined as physiological since they are involuntary; these were among the behaviors shown in response to food texture (pieces of vegetables or meat in the blended soup, a solid piece of potato in the mashed potato). In one specific case, this type of behavior was partially modified following desensitization treatment provided by a psychologist specialized in selective eating. During treatment, the focus of the work was directed at the patient's hypersensitivity to certain textures - vegetables and fruit in general, beans, and juices with residues. At the end of treatment, the mother managed to introduce various food items into the child's diet that had previously triggered the reactions described above and improved his tolerance to textures in various aspects:

... we noticed that he only drank juice when there were no fibers in it, nothing. It was well-sieved pineapple juice, passion fruit juice, grape juice. He wouldn't take mango juice, cashew fruit juice, hog plum juice, any of those with fibers in them. (Mother 6, boy 7 years) 
5) Reaction to new kinds of foods. Attempts to introduce different foods may generate reactions to the new foods that may or may not include an outright refusal. These reactions will affect the future behavior of the mothers. Attitudes of resistance were more common. Some children spit out the food, and became irritated and aggressive just from being offered the food. They would often say "I don't like it" or "I don't want it" without even having tried the food. Others pushed the spoon/fork away or pushed away the hand of whoever was offering them the food, in a reaction of obvious and even aggressive refusal. More flexible attitudes were less common. In these cases, first the child smelled the food and then put a very small piece in their mouth. These children were more likely to accept the food offered.

\section{Discussion}

\section{Child's eating patterns}

The majority of the mothers reported having stopped breastfeeding early or having had to introduce supplementary feeding because the infant refused to breastfeed. The mothers' main assumption was that the child refused to breastfeed because he/she had difficulty sucking. In a case-control study with 102 ASD cases and 102 matched healthy controls, the reports of the women interviewed suggested that the early weaning of their children may have been related to the onset of the symptoms of ASD. ${ }^{19} \mathrm{Al}$-Farsi et al. ${ }^{19}$ found a positive association between ASD and breastfeeding practices considered unfavorable such as a shorter period of exclusive breastfeeding.

Difficulty with sucking, both from the breast and from a bottle, was reported in cases in which breastfeeding was interrupted or formula milk was introduced at an early stage. As the children grew up, difficulties with sucking may have progressed into chewing and swallowing problems, contributing to their food choices. Other studies have mentioned the occurrence of problems related to the mechanics of chewing and swallowing in children with ASD. ${ }^{20,21}$ It is reasonable to speculate that the early discontinuation of breastfeeding may have resulted in a reduction in the stimulus required to develop the muscles of the face and mouth, negatively affecting the mechanisms of chewing and swallowing. Nevertheless, not all the mothers mentioned difficulties related to sucking, chewing and swallowing, and this may suggest the existence of a subgroup of individuals with ASD with specific abnormalities in the tonicity of the muscles of the face and mouth. Of course, this qualitative study does not allow inferences to be made regarding causality, and it is important to mention that any observations in this respect are in fact mere speculation.

In various segments of the mothers' narratives, peculiarities identified in the children's eating habits were probably related to the characteristics of ASD. Sensory dysfunction, a common characteristic of ASD, was expressed as hypersensitivity to smells and textures, leading to a refusal to eat certain foods. Hazen et al. ${ }^{22}$ and Cermak et al. ${ }^{4}$ estimated the prevalence of sensory processing disorders to range from 69 to $95 \%$ in children of various ages with ASD. In this study, however, the dietary profile of the children reflected the families' preferences. A study conducted with typical children also showed that the children's eating habits reflected those of their parents. ${ }^{23}$

\section{Family's attitudes}

The mothers' narratives indicate that when their food choices are based on healthy options, this is reflected in the children's routine diet. Studies that analyzed the formation of eating habits have shown that the parents exert a significant influence on the development of their children's behavior. ${ }^{24-26}$ Skinner et al. ${ }^{27}$ analyzed children's food preferences and found that the mothers did not offer their children food that they themselves did not like, and that the children were less likely to reject the food that their mothers most enjoyed.

Some mothers give in faster to their children's dietary demands and make many exceptions, allowing the children to choose what they want to eat. This permissiveness appears to be supported by the mother's belief that the eating habits of children with ASD are selective and restrictive. According to Birch, ${ }^{28}$ when given the opportunity to choose, our genetic predisposition induces us to reject anything that is new. Also, we tend to choose foods with a sweet or savory taste, foods that are part of a social context and foods that, when eaten, are followed by a positive sensation, e.g., high-energy foods consumed when the individual is hungry. ${ }^{28}$ Therefore, food preferences are part of the arsenal of every human being and every child, but can be confused with the specific selectivity of autism. At the same time, shielded by ASD, parents may give up on their attempts to impose a more rigid dietary education and yield to their children's preferences.

\section{Food-related behavior}

Some characteristics inherent to autism such as sensory hypersensitivity and behavioral rigidity that induce individuals to refuse novel experiences are reflected in the behaviors of food refusal and food selectivity in children with ASD. ${ }^{3,6}$ The mothers' narratives 
reflect these difficulties that are intrinsic to ASD; however, they also indicate that these characteristics may not be determinant when adequate environmental stimulus successfully results in the introduction of new eating habits.

Several of the mothers' narratives suggested that the children use inappropriate behavior as a strategy to ensure that they will get what they want to eat and reject anything that they do not want or anything that is being offered for the first time. According to the mother's reasoning, her fear that the child will not eat anything obliges her to allow the child to eat anything at all or even encourage him/her to eat something that the mother believes he/she will prefer. In this way, depending on the child's preferences and the attitudes of the family, a vicious cycle may be installed with respect to the dynamics of eating. In the first instance, the food preferred by the child (or the food that the child's parents suppose will please him/her) is immediately offered and also used as a bargaining chip. Next, the child systematically refuses any food that is not part of his/her preferences so that the main meals (lunch and dinner) are replaced with snacks with low nutritional value. A restricted diet is then established, the contents of which were defined by the dialect between the attitudes of the child and those of the family with respect to food. During the course of this cycle, the child begins to exert pressure to obtain specific foods by crying insistently, self-mutilating and screaming if speech has not yet been established. Some mothers reported that the children's attitude changed completely when they were alone with their father, indicating the possibility that the person taking care of the child is reinforcing the inappropriate eating behavior. Some studies suggest that the prevalence of anxiety in the mothers of individuals with ASD is high and could be contributing to more permissive behaviors in relation to the children's requests rather than the adoption of a more educational stance, even with respect to dietary training. ${ }^{13,29-31}$

\section{Conclusion}

The present results show that although organic factors such as sensory sensitivity and difficulty in sucking or chewing may affect the child's choice of foods, environmental factors may also be determinant, either reinforcing food selectivity or favoring a healthier and more diverse diet. This finding enables interventions to be designed that would favor the implementation of healthier habits. Educational and preventive programs should target the parents of children with ASD, since these children may also model their eating behavior on the family habits and lifestyle or on the attitudes of their parents/caregivers with respect to food.

\section{Acknowledgments}

This research was supported by Fundação de Amparo à Pesquisa do Estado da Bahia (FAPESB; grant 029/2012; PET 0012/2013). The first author received a grant from Programa de Suporte à Pós-Graduação de Instituições de Ensino Particulares (PROSUP), Coordenação de Aperfeiçoamento de Pessoal de Nível Superior (CAPES). The authors gratefully acknowledge the collaboration of Rita Valéria Brazil, president of Associação de Amigos do Autista da Bahia (AMA-BA) and thank all the parents who participated anonymously in the survey.

\section{Disclosure}

No conflicts of interest declared concerning the publication of this article.

\section{References}

1. Narzisi A, Muratori F, Calderoni S, Fabbro F, Urgesi C. Neuropsychological profile in high functioning autism spectrum disorders. J Autism Dev Disord. 2013;43:1895-909.

2. Sacrey LA, Armstrong VL, Bryson SE, Zwaigenbaum L. Impairments to visual disengagement in autism spectrum disorder: a review of experimental studies from infancy to adulthood. Neurosci Biobehav Rev. 2014;47:559-77.

3. Ranjan S, Nasser JA. Nutritional status of individuals with autism spectrum disorders: do we know enough? Adv Nutr. 2015;6:397407.

4. Cermak SA, Curtin C, Bandini LG. Food selectivity and sensory sensitivity in children with autism spectrum disorders. J Am Diet Assoc. 2010;110:238-46.

5. Marí-Bauset S, Zazpe I, Mari-Sanchis A, Llopis-González A, Morales-Suárez-Varela M. Food selectivity in autism spectrum disorders: a systematic review. J Child Neurol. 2014;29:1554-61.

6. Zobel-Lachiusa J, Andrianopoulos MV, Mailloux Z, Cermak SA. Sensory differences and mealtime behavior in children with autism. Am J Occup Ther. 2015;69:6905185050.

7. Ledford JR, Gast DL. Feeding problems in children with autism spectrum disorders: a review. Focus Autism Other Dev Disabl. 2006;21:153-66.

8. Sharp WG, Jaquess DL, Morton JF, Herzinger CV. Pediatric feeding disorders: a quantitative synthesis of treatment outcomes. Clin Child Fam Psychol Rev. 2010;13:348-65.

9. Pondé MP, Rousseau C. Immigrant children with autism spectrum disorder: the relationship between the perspective of the professionals and the parents point of view. J Can Acad Child Adolesc Psychiatry. 2013;22:131-8.

10. Rogers LG, Magill-Evans J, Rempel GR. Mothers' challenges in feeding their children with autism spectrum disorder - managing more than just picky eating. J Dev Phys Disabil. 2012;24:19-33.

11. Suarez MA, Atchison BJ, Lagerwey M. Phenomenological examination of the mealtime experience for mothers of children with autism and food selectivity. Am J Occup Ther. 2014;68:102-7.

12. Curtin C, Hubbard K, Anderson SE, Mick E, Must A, Bandini LG. Food selectivity, mealtime behavior problems, spousal stress, and family food choices in children with and without autism spectrum disorder. J Autism Dev Disord. 2015;45:3308-15. 
13. Machado Junior SB, Celestino MI, Serra JP, Caron J, Pondé MP. Risk and protective factors for symptoms of anxiety and depression in parents of children with autism spectrum disorder. Dev Neurorehabil. 2016;19:146-53.

14. Barker ET, Hartley SL, Seltzer MM, Floyd FJ, Greenberg JS, Orsmond GI. Trajectories of emotional well-being in mothers of adolescents and adults with autism. Dev Psychol. 2011;47:55161.

15. Davis NO, Carter AS. Parenting stress in mothers and fathers of toddlers with autism spectrum disorders: associations with child characteristics. ] Autism Dev Disord. 2008;38:1278-91.

16. Greenberg JS, Seltzer MM, Hong J, Orsmond GI. Bidirectional effects of expressed emotion and behavior problems and symptoms in adolescents and adults with autism. Am J Ment Retard. 2006;111:229-49.

17. Creswell JW. Qualitative inquiry \& research design: choosing among five approaches. 3rd ed. London: SAGE Publications; 2012.

18. Gibbs G. Análise de dados qualitativos. Porto Alegre: ArtMed; 2009.

19. Al-Farsi YM, Al-Sharbati MM, Waly MI, Al-Farsi OA, Al-Shafaee MA, Al-Khaduri MM, et al. Effect of suboptimal breast-feeding on occurrence of autism: a case-control study. Nutrition. 2012;28:e27-32.

20. Diolordi L, Del Balzo V, Bernabei P, Vitiello V, Donini LM. Eating habits and dietary patterns in children with autism. Eat Weight Disord. 2014;19:295-301.

21. Seiverling L, Hendy HM, Williams K. The Screening Tool of Feeding Problems Applied to Children (STEPCHILD): psychometric characteristics and associations with child and parent variables. Res Dev Disabil. 2011;32:1122-9.

22. Hazen EP, Stornelli JL, O'Rourke JA, Koesterer K, McDougle CJ. Sensory symptoms in autism spectrum disorders. Harv Rev Psychiatry. 2014;22:112-24.

23. Anzman-Frasca S, Savage JS, Marini ME, Fisher JO, Birch LL. Repeated exposure and associative conditioning promote preschool children's liking of vegetables. Appetite. 2012;58:54353.

24. Hendrie G, Sohonpal G, Lange K, Golley R. Change in the family food environment is associated with positive dietary change in children. Int J Behav Nutr Phys Act. 2013;10:4.

25. Scaglioni S, Arrizza C, Vecchi F, Tedeschi, S. Determinants of children's eating behavior. Am J Clin Nutr. 2011;94:2006S-11S.

26. Scaglioni S, Salvioni M, Galimberti, C. Influence of parenta attitudes in the development of children eating behaviour. $\mathrm{Br}$ J Nutr. 2008;99:S22-5.

27. Skinner JD, Carruth BR, Wendy B, Ziegler PJ. Children's food preferences: a longitudinal analysis. J Am Diet Assoc. 2002;102:1638-47.

28. Birch LL. Development of food preferences. Annu Rev Nutr. 1999;19:41-62.

29. Piven J, Chase GA, Landa R, Wzorek M, Gayle J, Cloud D, et al. Psychiatric disorders in the parents of autistic individuals. J Am Acad Child Adolesc Psychiatry. 1991;30:471-8.

30. Almansour MA, Alateeq MA, Alzahrani MK, Algeffari MA, Alhomaidan HT. Depression and anxiety among parents and caregivers of autistic spectral disorder children. Neurosciences (Riyadh). 2013;18:58-63.

31. Ou WX, Cha CH, Wang LH. Mental health state of parents of children with autism. Zhongguo Dang Dai Er Ke Za Zhi. 2010;12:947-9.

\section{Correspondence:}

Cristiane Pinheiro Lázaro

Laboratório Interdisciplinar de Pesquisa em Autismo (LABIRINTO)

Escola Bahiana de Medicina e Saúde Pública (BAHIANA)

Av. D. João VI, 295, Brotas

40290-000 - Salvador, BA, Brazil

Tel.: (71) 2101-1901

E-mail: lazarocris@hotmail.com 